\title{
Clinical Demographic Association and Outcome in Patients with Aneurysmal Subarachnoid Hemorrhage
}

\author{
Mayank Bansal $^{1} \quad$ R. S. Mittal ${ }^{1}$ \\ ${ }^{1}$ Department of Neurosurgery, Sawai Man Singh Medical College and \\ Hospital, Jaipur, Rajasthan, India \\ Indian J Neurosurg 2015;4:63-68.
}

Address for correspondence Dr. Mayank Bansal, MCh, Department of Neurosurgery, Sawai Man Singh Medical College, Jaipur 302004, Rajasthan, India (e-mail: mayankbansal201@gmail.com).

\begin{abstract}
Keywords

- aneurysm

- subarachnoid hemorrhage

- clipping

- Hunt and Hess grade

Introduction Even in this modern era of neurosurgery, we could not achieve 0\% mortality in operated aneurysmal subarachnoid hemorrhage (SAH) patients. An analysis of factors affecting outcome was never published in detail, and a recent update of guidelines for management of aneurysm SAH noted deficiency in knowledge about this issue.

Objective The study aims to assess the effect of various factors on the outcome of operated aneurysmal SAH patients.

Methods The various factors regarding age, sex, associated chronic diseases, clinical condition of patients, surgery interval, and nature of aneurysm were correlated with outcomes of 345 operated aneurismal SAH patients. Statistical analysis was done by chi-square test and logistic regression.

Results As per grade, patients' survival is $80.16 \%$ for fair grade and $21.65 \%$ for poor grade, which was statistically significant $(p<0.001)$. No significant difference was observed for other factors analyzed independently $(p>0.05)$. On comparing with Hunt and Hess $(\mathrm{H}-\mathrm{H})$ grade, all the above-mentioned variables showed significantly better survival in fair grade than in poor grade $(p<0.05)$. The Wald criteria demonstrated that only $\mathrm{H}-\mathrm{H}$ grade made a significant contribution to prediction.

Conclusion Although a number of factors seem to affect the outcome of aneurismal SAH patients, it is the grade at presentation, which comes out to be an independent variable, influencing the outcome of patients. Patients presented with fair grade tend to have better outcome than those presented with poor grade. All other factors do not have significant impact over the outcome of clipped aneurysm patients with SAH.
\end{abstract}

\section{Introduction}

The incidence of serious cerebrovascular conditions has substantially decreased in the last three decades, ${ }^{1}$ but the incidence of aneurysmal subarachnoid hemorrhage (SAH), however, has not changed and remains approximately 1 per 10,000 people annually. ${ }^{2,3}$ SAH because of the rupture of an intracranial aneurysm is a potentially fatal event. Although it accounts for $5 \%$ of all strokes but its burden is relevant due to high mortality, high disability, and higher incidence in the young. ${ }^{4}$ Among those who suffer aneurysmal SAH, $12 \%$ may die before seeking medical attention and $40 \%$ die within the first month after the bleeding. ${ }^{5}$

Despite the great advances in diagnostic modalities and availability of dedicated neurosurgical care, mortality of aneurysm surgery is still high and $0 \%$ mortality has not been received

August 5, 2014

accepted

May 25, 2015

published online

July 29, 2015
DOI http://dx.doi.org/

10.1055/s-0035-1558966. ISSN 2277-954X.
(C) 2015 Neurological Surgeons' Society of India
License terms

(이요 $\Theta \circledast$ 
achieved yet. ${ }^{6}$ Case fatality rate for SAH is still reported between 8.3 and $66.7 \%$, with most patients dying as a result of the initial bleed or its immediate complications. ${ }^{7}$

Analysis of factors affecting outcome has never been published in detail. ${ }^{8}$ Several studies have been made to examine factors that affect outcome after aneurysmal SAH, but only three included sufficient patients to allow analysis of the effect of multiple independent factors. ${ }^{8-10} \mathrm{~A}$ recent update of guidelines for management of aneurysm SAH noted deficiency in knowledge regarding this issue. ${ }^{10}$ There are several reports from India regarding the outcome after surgical clipping or coiling of aneurysms, but few reports present the overall outcome of all patients with SAH. ${ }^{5,7,11,12}$

Most of the previous studies done having inconsistence agreement regarding the influence of various clinicodemographic factors as well as nature of pathology to the overall outcome of the patients but clinical grade admission seems to be the most reliable one.

The study was conducted with the aim to test the effect of various clinicodemographic factors on the outcome of operated aneurysmal patients with SAH and to find out the most reliable factor predicting the outcome (survival).

\section{Patients and Methods}

This study is an observational descriptive study. The study was conducted from June 2013 to July 2014 (almost 1 year) and the study was conducted at Department of Neurosurgery of Sawai Man Singh Medical College and Hospital, Jaipur. A total of 345 patients (1985-2013) who underwent aneurysmal clipping (SUGITA CLIP) were included in the study. Data were collected retrospectively through case files.

All patients operated for aneurysmal clipping were included in the study and all those patients not operated either because of very low general medical condition/ hemodynamic instability and preferentially referred patients for endovascular management were excluded from study.

Almost all the cases were operated by single, most experienced neurosurgeon in the department, to compound the expertise and skill bias. All patients were managed in dedicated neurosurgery intensive care unit during postoperative period, treated with intravenous nimodipine. Outcome was analyzed in terms of whether patient survived (irrespective of neurological status) or expired.

\section{Preintervention Assessment}

All patients presented in Sawai Man Singh hospital emergency as either case of stoke or head injury. All these patients initially got plain computed tomographic (CT) head and $\mathrm{CT}$ angio brain done. Four-vessel digital subtraction angiography was done for those patients in whom either CT angiography was negative and suspicion was high or further information with respect to aneurysmal morphological configuration and spatial orientation was desired by the treating neurosurgeon.

The various clinicodemographic factors, that is, age, sex, and associated chronic illness in patients were assessed.
Surgical delay was calculated by considering difference between onset of ictus and date of surgery. Characteristic of aneurysm were defined regarding number and site of aneurysm. The sites considered were aneurysms involving either anterior circulation (anterior communicating artery [ACOM], internal carotid artery [ICA], middle cerebral artery [MCA], distal anterior cerebral artery [DACA], and posterior communicating artery [PCOM]) or posterior circulation (posterior inferior cerebellar artery [PICA] and vertebral arteries [VCA]). Preoperative clinical condition was graded from 0 to 5 , according to Hunt and Hess grading scale $(\mathrm{H}-\mathrm{H}$ grade), further categorized into fair grade ( $\mathrm{H}-\mathrm{H}$ grades 1,2 , and 3), and poor grade ( $\mathrm{H}-\mathrm{H} 4$ and 5).

All the patients underwent baseline work-up and preanesthetic check-up, and they were optimized for the intervention. The patients in the poor grade were managed initially with conservative measures with supportive measures, including ventilatory support (if required). Any cause for poor neurological status was addressed; for example, hydrocephalus was managed with either a ventriculoperitoneal shunt or external ventricular drain.

A few patients with poor grade come to us after a considerable delay (referral delay), in later half of vasospasm period, we managed them conservatively initially till subsidence of expected vasospastic period and then were considered for surgical intervention if found appropriate.

\section{Statistical Analysis}

The qualitative or categorical variables were described as frequencies, proportion and percentage, and the quantitative data were presented as mean ( \pm standard deviation $[S D]$ ). Difference in proportions was compared using chi-square test. Logistic regression analysis was performed to predict the survival of aneurysmal patients with SAH with various variables. All statistical tests were two-sided and a probability value $<0.05$ was taken as significant.

\section{Results}

This study included 345 patients operated for aneurysmal clipping, of which 176 were males (51\%) and 169 were females (49\%) with a mean age of $45.43 \pm 12.47$ years (-Fig. 1), and 180 patients presented with associated comorbidities such as hypertension, diabetes, etc.

Among 345 operated patients, 284 patients were in fair grade and 61 were in poor grade. In our study, most common site for aneurysm was found to be situated at ACOM followed by MCA, and then ICA. Multiple aneurysms constituted $8.11 \%$ of the total.

Most of our patients (199) presented within vasospastic period (5-20 days), with 136 patients presented less than 4 days and a few presented after a considerable delay (> 21 days). Mean surgical interval was 6.5 days with $\mathrm{SD} \pm 4.3$ (-Table 1 ).

A logistic regression analysis was done to predict survival for 345 patients of aneurysmal SAH using age, sex, number of aneurysm, $\mathrm{H}-\mathrm{H}$ grade, treatment delay, and comorbidity as predictors. A test of full model was statistically significant 
indicating that the predictors as asset reliably distinguish between survival and death outcome. (chi-square, 62.127; $\mathrm{d} f, 6 ; p<0.000)$. Also, the Hosmer and Lemshow test shows a good fit by high $p$-value and low chi-square value (chisquare 15.384 , df $8, p<0.052$ ). NegelKerke $R^{2}$ of 0.237 indicates fair relationship between predictors and grouping. Prediction success overall was 78.6\% (for survival 93.2\% and for death $40.2 \%)$. The Wald criteria demonstrated that only $\mathrm{H}-\mathrm{H}(p>0.00)$ made a significant contribution to prediction. Other predictors were found to be not significant.

$\mathrm{H}-\mathrm{H}$ as predictor: exponential value 0.428 indicated that when $\mathrm{H}-\mathrm{H}$ is raised by one unit, the odds ratio is 0.428 times as large and therefore patients are 0.428 times more likely to survive (-Table $\mathbf{2}$ ).

\section{Discussion}

To predict the outcome in patients operated for aneurysmal $\mathrm{SAH}$, surgeons have investigated the factors influencing the treatment outcome, but there are still disputes in literature about the majority of such factors. ${ }^{13}$ No agreements have yet been reached about the ideal timing for surgery ${ }^{8-10,14}$ nor about the dependence of the postoperative outcome associated with aneurysmal size and site $\mathrm{e}^{13,15-17}$ patient's gender and age $8,9,11,13,15$ chronic diseases $9,13,15$ preoperative clinical condition (-Fig. 2). $5,7,10,11,15,17-22$

As per grade, patients' survival is $80.16 \%$ for fair grade and $21.65 \%$ for poor grade which was statistically significant $(p<0.001)$. As $\mathrm{H}-\mathrm{H}$ grade increases, survival becomes significantly poorer. This fact is supported by most of the studies done in past. $5,7,10,11,15,17-22$

Bonilha et al in $2001^{18}$ performed a prospective study in patients with ruptured aneurysm and observed that the clinical condition (H-H scale) assessed upon the moment of surgery showed significant correlation $(p=0.0002)$ with outcome.

Rosengart et al in $2007^{15}$ analyzed data from 3,567 patients with aneurysmal SAH enrolled in four randomized clinical trials and concluded that unfavorable outcome was associated with worsening neurological grade.

A recent prospective study was conducted in Post Graduate Institute of Medical Education \& Research,

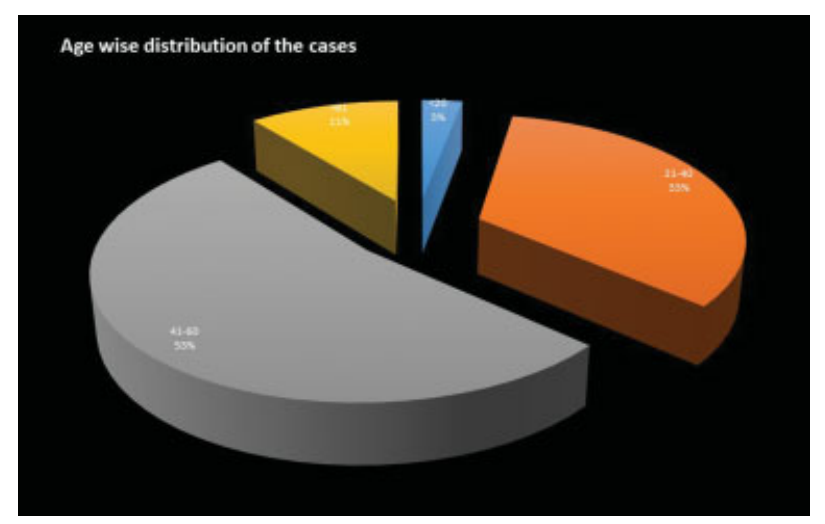

Fig. 1 Age wise distribution of the cases.
Chandigarh, by Harsimrat Bir Singh Sodhi, ${ }^{7}$ during 10month period, including 330 patients, taken for intervention for ruptured aneurysm. The study shows that higher the grade at presentation was predictor of poor outcome (odds ratio [OR]: 35.1, 95\% confidence interval (CI): 10.8-114.7).

This study showed that survival becomes poorer as age advances. But statistical analysis showed no significant difference in outcome among different age group per se. When outcome was analyzed as per different grades, there was significantly good outcome in more than 20 years age group, in fair grade $(80 \%)$ then poor grade $(30 \%)$ ( $p$-value $<0.05)$, but younger than 20 years, grade does not have any impact ( $p=0.16 \mathrm{NS}$ ).

Duong et $\mathrm{al}^{23}$ reported good outcome in $87 \%$ of patients older than 60 years, $91 \%$ of those ranged between 30 and 59 years and in all the patients younger than 30 years.

Lanzino et al in $1996,{ }^{24}$ Rosengart et al in 2007, ${ }^{15}$ and Shingare et al in $2011^{11}$ concluded that poor outcome is associated with increasing age of patients whereas Roganović and Pavlićević in $2002^{13}$ contradict the issue by saying that age does not affect the outcome of the patients.

Better results younger than 20 years of age are probably because of the fact of better regenerative capacity/neural plasticity compared with adult ones.

Although overall survival seems to be better in male patients, $74.43 \%$ in comparison to $69.23 \%$ in females, statistically no significant difference was observed. Although significant differences were observed while comparing fair $\mathrm{H}-\mathrm{H}$ grade as compared with poor $\mathrm{H}-\mathrm{H}$ grade. Literature has contradictory opinion about the association of sex with outcome in patients with aneurysmal SAH. Some studies support the view $7,16,25$ while some oppose it. ${ }^{26}$

Of 345 patients, 180 patients presented with associated comorbidities such as hypertension, COPD, diabetes etc. Overall survival appears to be better in absence of comorbidities (72.22\%) as compared with its presence (71.51\%), but statistically no significant difference was observed between the two. When outcome compared according to grade, significant difference was observed in fair grade (80.98\%) as compared with poor grade $(29.52 \%)$ of $\mathrm{H}-\mathrm{H}$ scale $(p<0.001 \mathrm{HS})$.

Various congenital as well as acquired causes have been implicated in the etiology of aneurysm formation, among which hypertension is the most frequently studied risk factor associated with an increased risk of aneurysmal SAH as well as unruptured intracranial aneurysm. Patients with hypertension had a nearly sevenfold higher risk of aneurysmal SAH. ${ }^{26,27}$ Previous studies also having conflicting opinion about its association. Some study negatively correlate, ${ }^{13,15}$ and some does not reveal any association. $^{18}$

No significant difference was observed according to time interval between the date of ictus and the date of surgery with the outcome, but significant difference was observed in fair grade as compared with poor grade of $\mathrm{H}-\mathrm{H}$ scale in less than 20 days as compared with more than 20 days duration. 
Table 1 The survival in patients with various clinical grade

\begin{tabular}{|c|c|c|c|c|c|c|c|}
\hline S no & Variable & & No of patients & Survived & Expired & \% Survival & $p$-Value \\
\hline \multirow[t]{2}{*}{1} & \multirow[t]{2}{*}{ Sex } & Male & 176 & 131 & 45 & 74.43 & \multirow[t]{2}{*}{0.340 NS } \\
\hline & & Female & 169 & 117 & 52 & 69.2 & \\
\hline \multirow[t]{4}{*}{2} & \multirow[t]{4}{*}{ Age } & $<20$ & 10 & 9 & 1 & 90 & \multirow[t]{4}{*}{0.228 NS } \\
\hline & & $21-40$ & 116 & 82 & 34 & 70.68 & \\
\hline & & $41-60$ & 182 & 135 & 47 & 74.17 & \\
\hline & & $>60$ & 37 & 22 & 15 & 59.45 & \\
\hline \multirow[t]{2}{*}{3} & \multirow[t]{2}{*}{ Comorbidities } & Present & 165 & 118 & 47 & 71.51 & \multirow[t]{2}{*}{0.979 NS } \\
\hline & & Absent & 180 & 130 & 50 & 72.22 & \\
\hline \multirow[t]{3}{*}{4} & \multirow[t]{3}{*}{ Surgery interval } & $<4 d$ & 136 & 105 & 31 & 77.20 & \multirow[t]{3}{*}{$0.223 \mathrm{NS}$} \\
\hline & & $5-20 d$ & 199 & 134 & 65 & 67.33 & \\
\hline & & $>20 d$ & 10 & 9 & 1 & 90 & \\
\hline \multirow[t]{2}{*}{5} & \multirow[t]{2}{*}{ Grade } & Fair grade & 284 & 230 & 54 & 81.0 & $<0.001 \mathrm{HS}$ \\
\hline & & Poor grade & 61 & 18 & 43 & 29.50 & \\
\hline \multirow[t]{8}{*}{6} & \multirow[t]{8}{*}{ Site } & ACOM & 150 & 102 & 48 & 68.0 & \multirow[t]{8}{*}{0.308 NS } \\
\hline & & MCA & 76 & 60 & 16 & 78.94 & \\
\hline & & ICA & 40 & 31 & 9 & 77.5 & \\
\hline & & DACA & 17 & 12 & 5 & 70.58 & \\
\hline & & PCOM & 29 & 23 & 6 & 79.31 & \\
\hline & & PICA & 3 & 2 & 1 & 66.67 & \\
\hline & & VA & 2 & 1 & 1 & 50 & \\
\hline & & Multiple & 28 & 17 & 11 & 60.71 & \\
\hline
\end{tabular}

Abbreviations: ACOM, anterior communicating artery; DACA, distal anterior cerebral artery; ICA, internal carotid artery; MCA, middle cerebral artery; PCOM, posterior communicating artery; PICA, posterior inferior cerebellar artery; VA, vertebral arteries.

This fallacy can be explained by the fact that after the interval of 21 days, vasospasm subsides, patients are hemodynamically stable and usually having better brain homeostatic conditions and hence resulting in better outcome in both the grades. But this does not give the impression that every patient should be operated after 21 days as there is always a risk of rebleed and deterioration.

The controversy over the optimum timing of surgery for patients with aneurysmal SAH has continued for many years. Early clipping of an aneurysm prevents rebleeding, a

\section{Distribution of the cases according to $\mathrm{H} \& \mathrm{H}$ grade}

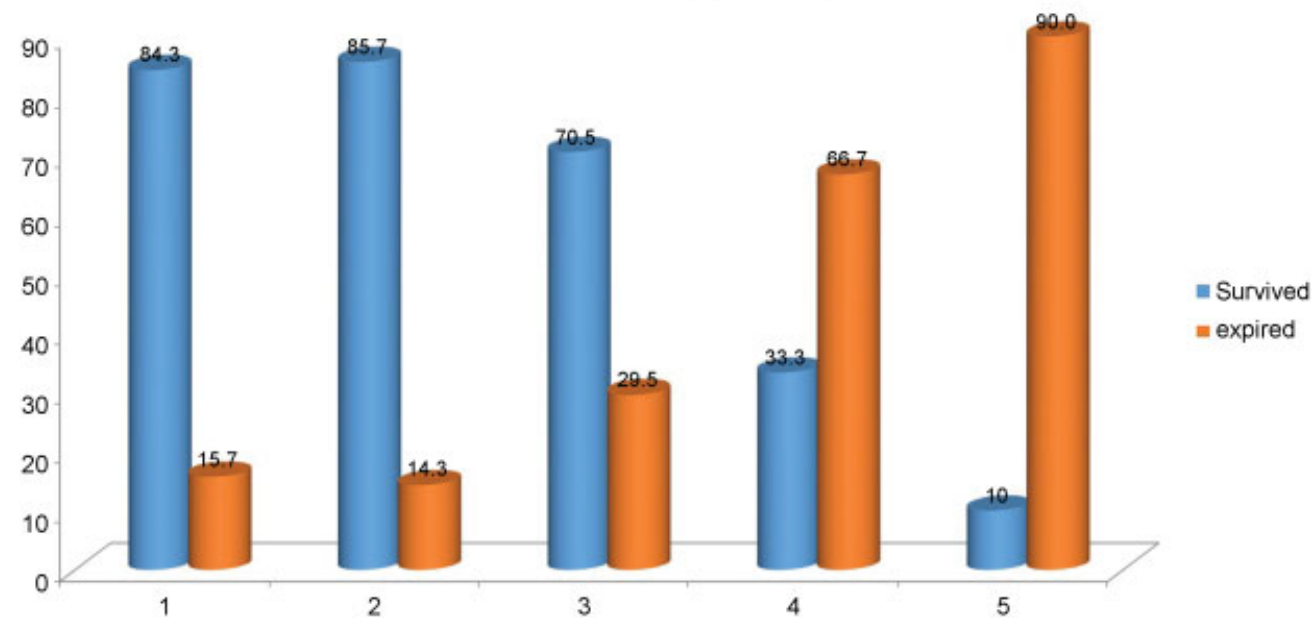

Fig. 2 Distribution of the cases according to $\mathrm{H}-\mathrm{H}$ grade. 
Table 2 Predictor of survival of aneurysmal patients with SAH with binary logistic regression

\begin{tabular}{|c|c|c|c|c|c|c|c|c|c|}
\hline \multicolumn{10}{|c|}{ Variables in the equation } \\
\hline & & \multirow[t]{2}{*}{ B } & \multirow[t]{2}{*}{ S.E. } & \multirow[t]{2}{*}{ Wald } & \multirow[t]{2}{*}{ df } & \multirow[t]{2}{*}{ Sig. } & \multirow[t]{2}{*}{$\operatorname{Exp}(B)$} & \multicolumn{2}{|c|}{$95 \% \mathrm{Cl}$ for $\operatorname{Exp}(\mathrm{B})$} \\
\hline & & & & & & & & Lower & Upper \\
\hline \multirow[t]{7}{*}{ Step $1^{a}$} & Age & 0.009 & 0.013 & 0.430 & 1 & 0.512 & 1.009 & 0.983 & 1.035 \\
\hline & Sex & -0.147 & 0.269 & 0.298 & 1 & 0.585 & 0.863 & 0.509 & 1.463 \\
\hline & Delay & -0.001 & 0.029 & 0.001 & 1 & 0.979 & 0.999 & 0.945 & 1.057 \\
\hline & $\mathrm{H}-\mathrm{H}$ & 0.848 & 0.124 & 47.099 & 1 & 0.000 & 2.335 & 1.833 & 2.975 \\
\hline & Aneurysm(1) & 0.091 & 0.480 & 0.036 & 1 & 0.850 & 1.095 & 0.428 & 2.805 \\
\hline & Comorbidity & -0.318 & 0.327 & 0.951 & 1 & 0.330 & 0.727 & 0.383 & 1.379 \\
\hline & Constant & -2.781 & 1.191 & 5.453 & 1 & 0.020 & 0.062 & & \\
\hline
\end{tabular}

Abbreviations: $\mathrm{Cl}$, confidence interval; $\mathrm{SAH}$, subarachnoid hemorrhage; $\mathrm{H}-\mathrm{H}$, Hunt and Hess.

a Variable(s) entered on step 1: age, sex, delay, $\mathrm{H}-\mathrm{H}$, aneurysm, comorbidity.

major cause of death after SAH. However, concerns about the possible deleterious effects of early surgery raise questions about the safety and efficacy of this approach. ${ }^{26}$

For fair grade patients, most of the studies accept that early surgery is going to improve the outcome. ${ }^{14,16,28}$ But evidence for the optimum timing of surgery in poor grade patents is still insufficient. ${ }^{29}$ The prognosis of poor grade patients is associated with significant morbidity and mortality. ${ }^{17,30}$ Without surgical intervention, the mortality rate of poor grade patients can reach more than $90 \%{ }^{31}$

Ohman and Heiskanen ${ }^{25}$ randomized 216 patients with $\mathrm{SAH}$ in clinical grades I to III (according to the $\mathrm{H}-\mathrm{H}$ classification) into the following three operational groups: acute (0-3 days after SAH), intermediate (4-7 days after $\mathrm{SAH}$ ), or late (after day 7). At 3 months post-SAH, clinical outcomes indicated that there was no difference in the prognosis of these three groups. In 2002, Ross et $\mathrm{al}^{32}$ indicated that there were no significant difference at discharge or 6 months between the early group (day 1-3), intermediate group (day 4-10), and late group (day 11-21). However, this study was only concerned with the prognosis of surgical patient and ignored the relationship between clinical grades, rebleeding, and prognosis.

In 2002, de Gans et $\mathrm{al}^{28}$, performed a systematic metaanalysis and showed that outcomes were better after early or intermediate surgery than after late surgery, in patients who were in good clinical condition at admission. For patients in poor clinical condition, results suggest only a trend toward a better outcome for early or intermediate surgery when compared with late surgery. So, timing of surgery cannot be designated as independent clinical variable determining the outcome in aneurysmal patients with SAH.

In this study, no significant difference was observed according to site of aneurysm with the outcome. To further refine the conclusion, outcome was assessed to various sites of aneurysm as per two different grades and results are significantly better outcome in ACOM, MCA, and ICA group in fair grade patients and no difference in outcome was found in patients with aneurysm at sites other than those aforementioned. We predict lesser aneurysmal SAH sequel such as vasospasm and also less brain manipulation while approaching anterior circulation when compared with posterior circulation aneurysms.

Rosengart et $\mathrm{al}^{15}$ in 2007 concluded that unfavorable outcome was associated with ruptured posterior circulation aneurysm. Shingare et $\mathrm{al}^{11}$ in 2011 concluded that aneurysmal bleeding from anterior or posterior circulation do not influence the immediate outcome of patients with SAH.

The assumption that surgical outcome in patients with SAH with multiple intracranial aneurysms is actually worse than with single aneurysm is controversial. ${ }^{23,33-37}$

Our result also apparently reflects that multiple aneurysm patients having poorer prognosis then having single aneurysm (single $81.2 \%$ vs. multiple $78.9 \%$ ) but no significant difference was observed between these two group with the outcome ( $p=0.23 \mathrm{NS}$ ).

Significant difference was observed in fair grade as compared with poor grade of $\mathrm{H}-\mathrm{H}$ scale in the presence of single or multiple aneurysms.

In the studies by Rinne et al in $1995,{ }^{34}$ Kaminogo et $\mathrm{al}^{19}$ in 2003, and Gaivas et $\mathrm{al}^{38}$ in 2011, patients with multiple intracranial aneurysms had a higher mortality than patients harboring single intracranial aneurysms.

However, Orz et $\mathrm{al}^{37}$ in 1996 reviewed surgical outcome of 221 cases with multiple intracranial aneurysms operated on during the years 1988 to 1994 . They reported that there is no significant difference in the outcome of patients with single or multiple aneurysms, if they present with SAH. However, there is a marked difference seen, if presented without SAH.

\section{Conclusion}

Although several factors seem to affect the outcome of patients with $\mathrm{SAH}$, it is the grade at presentation, which eligibles to be an independent variable influencing the outcome of patients. Patients presented with fair grade tend to have better outcome as compared with poor grade. All other factor such as age, gender, associated comorbidities, number, and site of aneurysm does not have significant impact in deciding the outcome of surgically clipped patients. 


\section{References}

1 Broderick JP, Phillips SJ, Whisnant JP, O'Fallon WM, Bergstralh EJ. Incidence rates of stroke in the eighties: the end of the decline in stroke? Stroke 1989;20(5):577-582

2 Phillips LH II, Whisnant JP, O'Fallon WM, Sundt TM Jr. The unchanging pattern of subarachnoid hemorrhage in a community. Neurology 1980;30(10):1034-1040

3 Ingall TJ, Whisnant JP, Wiebers DO, O'Fallon WM. Has there been a decline in subarachnoid hemorrhage mortality? Stroke 1989; 20(6):718-724

4 Feigin VL, Rinkel GJ, Lawes CM, et al. Risk factors for subarachnoid hemorrhage: an updated systematic review of epidemiological studies. Stroke 2005;36(12):2773-2780

5 Bhat AR, Afzalwani M, Kirmani AR. Subarachnoid hemorrhage in Kashmir: Causes, risk factors, and outcome. Asian J Neurosurg 2011;6(2):57-71

6 Nieuwkamp DJ, Setz LE, Algra A, Linn FH, de Rooij NK, Rinkel GJ. Changes in case fatality of aneurysmal subarachnoid haemorrhage over time, according to age, sex, and region: a meta-analysis. Lancet Neurol 2009;8(7):635-642

7 Sodhi HBS, Savardekar AR, Mohindra S, Chhabra R, Gupta V, Gupta SK. The clinical profile, management, and overall outcome of aneurysmal subarachnoid hemorrhage at the neurosurgical unit of a tertiary care center in India. J Neurosci Rural Pract 2014; 5(2):118-126

8 Kassell NF, Torner JC, Haley EC Jr, Jane JA, Adams HP, Kongable GL. The international cooperative study on the timing of aneurysm surgery. Part 1: overall management results. J Neurosurg 1990; 73(1):18-36

9 Torner JC, Kassell NF, Wallace RB, Adams HPJ Jr. Preoperative prognostic factors for rebleeding and survival in aneurysm patients receiving antifibrinolytic therapy: report of the Cooperative Aneurysm Study. Neurosurgery 1981;9(5): 506-513

10 Niskanen MM, Hernesniemi JA, Vapalahti MP, Kari A. One-year outcome in early aneurysm surgery: prediction of outcome. Acta Neurochir (Wien) 1993;123(1-2):25-32

11 Shingare A, Nadkar MY, Singh R. Study of patient characteristics/ profile and factors determining the (immediate) outcome in spontaneous subarachnoid hemorrhage. J Assoc Physicians India 2011;59:505-508

12 Siddiq F, Chaudhry SA, Tummala RP, Suri MF, Qureshi AI. Factors and outcomes associated with early and delayed aneurysm treatment in subarachnoid hemorrhage patients in the United States. Neurosurgery 2012;71(3):670-677, discussion 677-678

13 Roganović Z, Pavlićević G. Factors influencing the outcome after the operative treatment of cerebral aneurysms of anterior circulation. Vojnosanit Pregl 2002;59(5):463-471

14 Whitfield PC, Kirkpatrick PJ. Timing of surgery for aneurysmal subarachnoid haemorrhage. Cochrane Database Syst Rev 2001; (2):CD001697

15 Rosengart AJ, Schultheiss KE, Tolentino J, Macdonald RL. Prognostic factors for outcome in patients with aneurysmal subarachnoid hemorrhage. Stroke 2007;38(8):2315-2321

16 Goto Y, Yamagata S. Deteriorating factors on the outcome in patients with fair grade of subarachnoid hemorrhage (WFNS grade I and II) [in Japanese]. No Shinkei Geka 2006;34(6): 577-582

17 Hutchinson PJ, Power DM, Tripathi P, Kirkpatrick PJ. Outcome from poor grade aneurysmal subarachnoid haemorrhage-which poor grade subarachnoid haemorrhage patients benefit from aneurysm clipping? Br J Neurosurg 2000;14(2):105-109
18 Bonilha L, Marques EL, Carelli EF, et al. Risk factors and outcome in 100 patients with aneurysmal subarachnoid hemorrhage. Arq Neuropsiquiatr 2001;59(3B):676-680

19 Kaminogo M, Yonekura M, Shibata S. Incidence and outcome of multiple intracranial aneurysms in a defined population. Stroke 2003;34(1):16-21

20 Bazowski P, Gamrot J, Rudnik A, Konopka M. Analysis of selected prognostic factors in patients with ruptured cerebral aneurysms operated-on in the early period [in Polish]. Neurol Neurochir Pol 1992(Suppl 1):25-28

21 Gomis P, Rousseaux P, Jolly D, Graftieaux JP. Initial prognostic factors of aneurysmal subarachnoid hemorrhage [in French]. Neurochirurgie 1994;40(1):18-30

22 Shirao S, Yoneda H, Kunitsugu I, et al. Preoperative prediction of outcome in 283 poor-grade patients with subarachnoid hemorrhage: a project of the Chugoku-Shikoku Division of the Japan Neurosurgical Society. Cerebrovasc Dis 2010;30(2):105-113

23 Duong DH, Kolluri VR, Spittaler PJ, Sengupta RP. Risk Score Estimation: a new method to determine optimal timing of aneurysm clipping for improved management outcome. Neurol Res 1998;20(3):218-224

24 Lanzino G, Kassell NF, Germanson TP, et al. Age and outcome after aneurysmal subarachnoid hemorrhage: why do older patients fare worse? J Neurosurg 1996;85(3):410-418

25 Ohman J, Heiskanen O. Timing of operation for ruptured supratentorial aneurysms: a prospective randomized study. J Neurosurg 1989;70(1):55-60

26 Sardana V, Maheshwari D, Aseri RK. Subarachnoid hemorrhage: current overview. Int J Basic Applied Med Sci 2012;2(3):257-271

27 Kleinpeter G, Lehr S. Is hypertension a major risk factor in aneurysmal subarachnoid hemorrhage? Wien Klin Wochenschr 2002;114(8-9):307-314

28 de Gans K, Nieuwkamp DJ, Rinkel GJ, Algra A. Timing of aneurysm surgery in subarachnoid hemorrhage: a systematic review of the literature. Neurosurgery 2002;50(2):336-340, discussion 340-342

29 Zhang Q Ma L, Liu Y, et al. Timing of operation for poor-grade aneurysmal subarachnoid hemorrhage: study protocol for a randomized controlled trial. BMC Neurol 2013;13:108

30 Laidlaw JD, Siu KH. Poor-grade aneurysmal subarachnoid hemorrhage: outcome after treatment with urgent surgery. Neurosurgery 2003;53(6):1275-1280, discussion 1280-1282

31 Zubkov YN. Treatment of patients with intracranial arterial aneurysms in the haemorrhagic period. Neurol Res 1994;16(1):6-8

32 Ross N, Hutchinson PJ, Seeley H, Kirkpatrick PJ. Timing of surgery for supratentorial aneurysmal subarachnoid haemorrhage: report of a prospective study. J Neurol Neurosurg Psychiatry 2002;72(4):480-484

33 Vajda J. Multiple intracranial aneurysms: a high risk condition. Acta Neurochir (Wien) 1992;118(1-2):59-75

34 Rinne J, Hernesniemi J, Niskanen M, Vapalahti M. Management outcome for multiple intracranial aneurysms. Neurosurgery 1995;36(1):31-37, discussion 37-38

35 Mizoi K, Suzuki J, Yoshimoto T. Surgical treatment of multiple aneurysms. Review of experience with 372 cases. Acta Neurochir (Wien) 1989;96(1-2):8-14

36 Inagawa T. Surgical treatment of multiple intracranial aneurysms. Acta Neurochir (Wien) 1991;108(1-2):22-29

37 Orz Y, Osawa M, Tanaka Y, Kyoshima K, Kobayashi S. Surgical outcome for multiple intracranial aneurysms. Acta Neurochir (Wien) 1996;138(4):411-417

38 Gaivas S, Rotariu D, Iliescu B, Ziyad F, Apetrei C, Poeată I. Multiple intracranial aneurysms: incidence and outcome in a series of 357 patients. Rom. Neurosurg. XVIII 2011;4:450-455 